\title{
Efeito de bioestimulante no crescimento inicial e na produtividade de plantas de batata-doce
}

\author{
Amarílis Beraldo Rós ${ }^{1 *}$, Nobuyoshi Narita ${ }^{2}$,Humberto Sampaio de Araújo ${ }^{3}$ \\ http://dx.doi.org/10.1590/0034-737X201562050007
}

\section{RESUMO}

O uso de bioestimulantes na agricultura tem apresentado efeitos positivos sobre a produtividade de determinadas culturas. No entanto, são escassos os estudos com o uso desses produtos em culturas cuja porção comercial é composta por raízes. Neste trabalho, objetivou-se avaliar a influência de diferentes concentrações do bioestimulante Stimulate ${ }^{\circledR}$ sobre o crescimento inicial de plantas de batata-doce e sobre a produtividade de raízes tuberosas. Foram conduzidos dois experimentos, nos quais segmentos de ramas de batata-doce foram parcialmente imersos em soluções com bioestimulante. Na casa de vegetação, o delineamento experimental foi inteiramente ao acaso, em esquema fatorial 6 x 6 , sendo seis concentrações de biofertilizante $\left(0,3,6,9,12\right.$ e $\left.15 \mathrm{~mL} \mathrm{~L}^{-1}\right)$ e seis épocas de coleta (10, $19,28,37,46$ e 55 dias após o plantio) de raízes e folhas. No campo, o delineamento experimental foi em blocos ao acaso, sendo os tratamentos seis concentrações de bioestimulante $\left(0,3,6,9,12\right.$ e $\left.15 \mathrm{~mL} \mathrm{~L}^{-1}\right)$. A percentagem de segmentos enraizados não variou entre os tratamentos. O bioestimulante influenciou o número de raízes adventícias e de folhas por planta, mas não sua massa seca. A produtividade de raízes tuberosas não diferiu entre os tratamentos, sendo os valores médios de 25,5 e 22,3 t ha ${ }^{-1}$ para produtividades total e comercial, respectivamente. Assim, a utilização do bioestimulante interfere no número de raízes e de folhas de plantas de batata-doce, mas não favorece a produtividade de raízes tuberosas até a concentração de $15 \mathrm{~mL} \mathrm{~L}^{-1}$.

Palavras-chave: Ipomoea batatas (L.) Lam., regulador de crescimento, Stimulate ${ }^{\circledR}$, biorregulador.

\section{ABSTRACT}

\section{Biostimulant effect on the initial growth and yield of sweet potato}

The use of biostimulants in agriculture has shown positive effects on the yield of some crops. However, there are few studies on the use of these products in crops which commercialized parts are the roots. This study aimed to evaluate the influence of different concentrations of the biostimulant Stimulate ${ }^{\circledR}$ on the sweet potato initial growth and tuberous root yield. Two experiments were carried out using stem segments partially immersed in solutions containing biostimulant. In a greenhouse experiment, the experiment was arranged in a completely randomized $6 \mathrm{x}$ 6 factorial design, with six biostimulant concentrations $\left(0,3,6,9,12\right.$ and $\left.15 \mathrm{~mL} \mathrm{~L}^{-1}\right)$ and six collection times (10, $19,28,37,46$ and 55 days after planting) of roots and leaves. In the field, the experiment was arranged in a randomized block design, and the treatments consisted of six biostimulant concentrations $\left(0,3,6,9,12\right.$ and $\left.15 \mathrm{~mL} \mathrm{~L}^{-1}\right)$. The percentage of rooted segments was not affected by the treatments. The biostimulant influenced the number of roots and leaves, but their dry mass was not affected. The tuberous root yield was not different among treatments, with mean values of total and commercial yields equal to 25.5 and $22.3 \mathrm{t} \mathrm{ha}^{-1}$, respectively. Therefore, the biostimulant interferes in the number of roots and leaves, but it does not increase yield of tuberous root up to the concentration of $15 \mathrm{~mL} \mathrm{~L}^{-1}$.

Key words: Ipomoea batatas (L.) Lam., plant growth regulator, Stimulate ${ }^{\circledR}$, bioregulator.

\footnotetext{
Submetido em 24/10/2013 e aprovado em 10/07/2015.

${ }^{1}$ Agência Paulista de Tecnologia dos Agronegócios (APTA), Presidente Prudente, São Paulo, Brasil. amarilis@apta.sp.gov.br

${ }^{2}$ Agência Paulista de Tecnologia dos Agronegócios (APTA), Presidente Prudente, São Paulo, Brasil. narita@apta.sp.gov.br

${ }^{3}$ Agência Paulista de Tecnologia dos Agronegócios (APTA), Andradina, São Paulo, Brasil. humbertosaraujo@apta.sp.gov.br

*Autora para correspondência: amarilis@apta.sp.gov.br
} 


\section{INTRODUÇÃO}

Bioestimulante ou estimulante vegetal origina-se da mistura de dois ou mais reguladores vegetais ou de reguladores vegetais com outras substâncias (Castro \& Vieira, 2001). O produto comercial Stimulate ${ }^{\circledR}$ é um bioestimulante composto por ácido indolbutírico $\left(0,05 \mathrm{~g} \mathrm{~L}^{-1}\right)$, cinetina $\left(0,09 \mathrm{~g} \mathrm{~L}^{-1}\right)$ e ácido giberélico $\left(0,05 \mathrm{~g} \mathrm{~L}^{-1}\right)$, com demais ingredientes inertes. As giberelinas, auxinas e citocininas são hormônios que atuam na divisão e no alongamento celular, na quebra de dormência de gemas, no aumento dos tecidos meristemáticos e no transporte de nutrientes (Taiz \& Zeiger, 2006).

De acordo com o rótulo do Stimulate ${ }^{\circledR}$, sua utilização promove o crescimento e o desenvolvimento vegetais, com destaque para o maior enraizamento e, portanto, maior absorção de água e nutrientes pelas plantas. Isso foi confirmado em trabalho de Reghin et al. (2000), no qual a utilização de Stimulate $\mathrm{Mo}^{\circledR}$ promoveu incremento do número e comprimento de raízes de mudas de mandioquinha-salsa, e em estudo de Cato (2006), que mostrou que a aplicação de Stimulate ${ }^{\circledR}$ promoveu aumentos significativos sobre o acúmulo de matéria seca radicular de tomateiro.

$\mathrm{O}$ uso de bioestimulantes na agricultura tem mostrado, por meio de pesquisas, potencial para o aumento da produtividade de determinadas culturas, como feijão (Abrantes et al., 2011), soja (Bertolin et al., 2010), algodão (Albrecht et al., 2009), pimentão (Palangana et al., 2012), alface (Guimarães et al., 2006) e cana-deaçúcar (Miguel et al., 2009). No entanto, são escassos trabalhos com o uso desses produtos em culturas cuja parte comercial é subterrânea, embora alguns resultados sejam favoráveis à utilização de bioestimulantes. Um exemplo foi o trabalho conduzido por Reddy et al. (1991), no qual se verificou incremento de $43 \%$ na produção de batata, quando misturas de fitorreguladores (giberelinas, citocininas, auxinas e traços de nutrientes) foram aplicadas sobre as plantas, na dose de 7,5 $\mathrm{L} \mathrm{ha}^{-1}$; e esse resultado foi associado ao aumento do número de hastes, folhas e tubérculos.

A cultura da batata-doce apresenta expressiva importância no Brasil, sendo cultivada em 21 unidades da federação (IBGE, 2013). Suas raízes tuberosas constituem a porção comercializada e uma possibilidade para incrementar sua produtividade é a utilização de bioestimulantes que favoreçam maior enraizamento das plantas, seja por meio do maior volume de raízes tuberosas e, ou, raízes absorventes que poderiam ampliar a absorção de água e nutrientes, permitindo maior acúmulo de substâncias de reservas em raízes tuberosas.

Por essa razão, considerando-se a hipótese de que a aplicação de bioestimulante favorece o sistema radicular da cultura da batata-doce, objetivou-se verificar a influência de diferentes concentrações de bioestimulante sobre o crescimento inicial das plantas e a produtividade de raízes tuberosas da cultura da batata-doce.

\section{MATERIAL E MÉTODOS}

Foram realizados dois trabalhos na Agência Paulista de Tecnologia dos Agronegócios - Polo Alto Sorocabana, no município de Presidente Prudente, a $22^{\circ} 11^{\prime} \mathrm{S}$ e $51^{\circ} 23^{\prime}$ W Gr. O clima é Aw, segundo classificação de Köppen, apresentando duas estações bem definidas: verão quente e úmido e inverno ameno e seco. Os dados meteorológicos observados durante a condução do experimento no campo encontram-se na Figura 1.

Para a avaliação do crescimento inicial, plantas de batata-doce foram conduzidas em experimento em casa de vegetação envolta em tela plástica, de 03 de setembro a 28 de novembro de 2012 . Foram utilizados segmentos de ramas de batata-doce com $0,3 \mathrm{~m}$ de comprimento, obtidos de plantas da variedade Londrina cultivadas a campo. Os segmentos foram retirados da porção apical das ramas (até 0,6 m) e as folhas removidas com tesoura de poda, tomando-se o cuidado de não ferir as gemas.

Os segmentos tiveram sua porção basal $(0,10 \mathrm{~m})$ inserida em recipientes com soluções, com diferentes concentrações do bioestimulante Stimulate ${ }^{\circledR}$ por 15 minutos. Após secagem, parte dos segmentos $(0,06 \mathrm{~m})$ foi inserida em substrato comercial Bioplant ${ }^{\circledR}$, acondicionado em copos plásticos com $0,15 \mathrm{~m}$ de altura e capacidade para $700 \mathrm{~mL}$.

Os recipientes permaneceram sobre bancada. O material foi irrigado por todo o período do experimento. Foram avaliados o número e a massa seca de raízes adventícias (raízes que saíam diretamente do segmento plantado) e o de folhas (aquelas com limbo com dimensão igual ou superior a $1,5 \mathrm{~cm}$ ), a cada nove dias, no período de 10 a 55 dias após plantio (DAP). Para a obten-

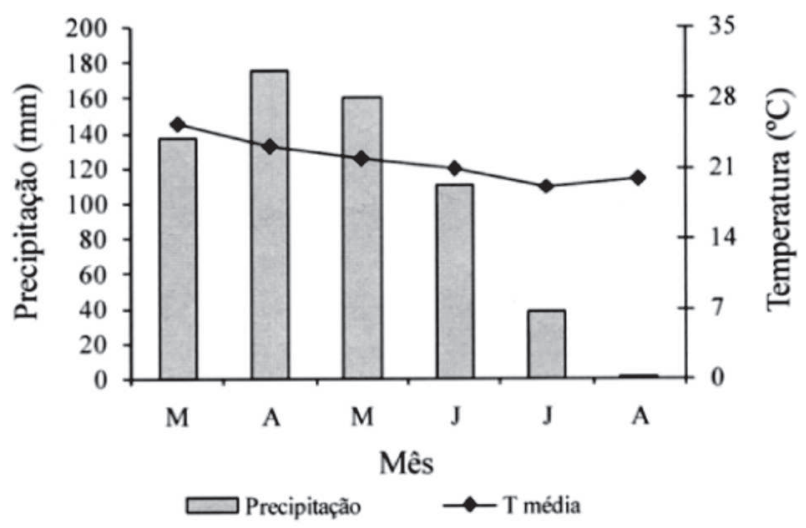

Figura 1: Precipitações e temperaturas médias ocorridas de março de 2013 a agosto de 2013. 
ção da massa seca, o material coletado (raízes e folhas) foi colocado em estufa com circulação forçada de ar, mantida à temperatura constante de $65{ }^{\circ} \mathrm{C}$, até a obtenção de valores constantes.

O delineamento experimental adotado foi inteiramente ao acaso, em esquema fatorial $6 \times 6$, sendo seis concentrações de biofertilizante $(0,3,6,9,12$ e $15 \mathrm{~mL}$ $\left.\mathrm{L}^{-1}\right)$ e seis épocas de coleta $(10,19,28,37,46$ e 55 DAP), com cinco repetições. Cada parcela foi constituída por dois recipientes com uma planta cada.

Os dados relativos à massa seca de raízes e folhas foram transformados mediante emprego da equação (x $+1)^{1 / 2}$, em função da presença de valores próximos a zero. Os dados obtidos foram submetidos a análises de variância e as médias foram ajustadas a equações de regressão polinomial. O critério para a escolha do modelo foi a significância pelo teste $\mathrm{F}$, a $5 \%$ de probabilidade de erro, e os maiores valores do coeficiente de determinação $\left(\mathrm{R}^{2}\right)$. Os pontos de máximos e mínimos foram determinados por derivação das equações de regressão.

Para avaliar a produtividade de raízes tuberosas de batata-doce, foi conduzido um experimento no campo. $\mathrm{O}$ delineamento experimental foi em blocos ao acaso, sendo os tratamentos compostos por seis concentrações de bioestimulante $\left(0,3,6,9,12\right.$ e $\left.15 \mathrm{~mL} \mathrm{~L}^{-1}\right)$, com cinco repetições. Os segmentos de ramas de batata-doce foram preparados segundo os mesmos procedimentos descritos anteriormente, mas permaneceram nas soluções com bioestimulante por 30 minutos. Após a secagem dos segmentos, esses foram plantados, em março de 2013, em área de Argissolo Vermelho-Amarelo, com o seguinte resultado de análise química na camada 0 a $0,15 \mathrm{~m}$ : $\mathrm{pH}\left(\mathrm{CaCl}_{2}\right.$ 1,0 $\left.\mathrm{mol} \mathrm{L}^{-1}\right) 5,2 ; 41,2 \mathrm{mg} \mathrm{dm}^{-3} \mathrm{de}_{\text {Mehlich }} ; 6,1 \mathrm{~g}$ $\mathrm{dm}^{-3}$ de C; 3,04 $\mathrm{cmol}_{\mathrm{c}} \mathrm{dm}^{-3} \mathrm{de} \mathrm{H}+\mathrm{Al} ; 0,3 \mathrm{cmol}_{\mathrm{c}} \mathrm{dm}^{-3} \mathrm{de}$ $\mathrm{K} ; 1,4 \mathrm{cmol}_{\mathrm{c}} \mathrm{dm}^{-3}$ de Ca; $1,18 \mathrm{cmol}_{\mathrm{c}} \mathrm{dm}^{-3} \mathrm{de} \mathrm{Mg} ; 47 \%$ de saturação por bases.

O solo foi preparado por meio de aração, gradagem e confecção de leiras com sulcador. Cada parcela experimental de $16,2 \mathrm{~m}^{2}$ foi composta por três leiras distanciadas $0,9 \mathrm{~m}$, onde foram plantadas 20 ramas de $0,3 \mathrm{~m}$ cada, espaçadas a cada $0,3 \mathrm{~m}$, o que correspondeu a 37.000 plantas $\mathrm{ha}^{-1}$. O plantio nas leiras, com altura aproximada de $0,35 \mathrm{~m}$, foi realizado com abertura manual de cova com $0,08 \mathrm{~m}$ de profundidade, colocação vertical da base da rama e enterrio também manual.

Aos 150 dias após plantio, foi realizada a colheita das raízes tuberosas da área útil, ou seja, das 16 plantas centrais da leira do meio. Foram avaliadas as produtividades total e comercial. Para produtividade total foram consideradas todas as raízes tuberosas com massa fresca igual ou superior a $40 \mathrm{~g}$, enquanto, para a produtividade comercial, as raízes tuberosas com massa fresca entre 80 e 1.000 $\mathrm{g}$ e bom aspecto (formato uniforme e liso).
Os dados obtidos foram submetidos a análises de variância. Adotou-se 5\% de probabilidade de erro.

\section{RESULTADOS E DISCUSSÃO}

A batata-doce apresentou $98 \%$ de suas estacas enraizadas e com brotações, não havendo diferença estatística na percentagem de estacas enraizadas em função das concentrações do bioestimulante. O elevado número de estacas enraizadas era esperado, visto que, de acordo com Rós et al. (2011), as estacas dessa cultura apresentam facilidade de enraizamento e de emissão de folhas, podendo atingir a percentagem de $100 \%$ de estacas enraizadas, dependendo da variedade.

Houve interação entre concentrações e épocas de coleta para a variável número de raízes por planta, nas épocas 28, 37 e 55 DAP. Nas épocas 10,19 e 46 DAP, o valor médio do número de raízes foi de 13,8; 12,5 e 26,6 unidades por planta, respectivamente. O número de raízes aos 28 DAP apresentou resposta segundo modelo linear, com diminuição de seu valor com o aumento das doses do bioestimulante (Figura 2). Aos 37 e 55 DAP, o comportamento dessa variável seguiu modelo quadrático, com diminuição do número de raízes até as doses de 7,2 e 7,1 $\mathrm{mL} \mathrm{L}^{-1}$, respectivamente. Após o ponto de mínimo, o número de raízes aumentou com o incremento das doses do bioestimulante.

Em trabalho de Reghin et al. (2000), o comportamento foi diferente, pois quando foram testadas concentrações de Stimulate $\mathrm{Mo}^{\circledR}$ em mudas de mandioquinha salsa, foi verificado que, até a concentração de $10 \mathrm{~mL} \mathrm{~L}^{-1}$, o número de raízes apresentou resposta segundo modelo linear, com acréscimos a cada aumento da concentração de bioestimulante.

Quanto à massa seca de raízes, não houve interação entre os tratamentos. Essa variável não foi influenciada pela aplicação de bioestimulante, apresentando valor médio de 1,88 g por planta, mas variou entre as épocas de coleta (Figura 3). A resposta estimada seguiu modelo

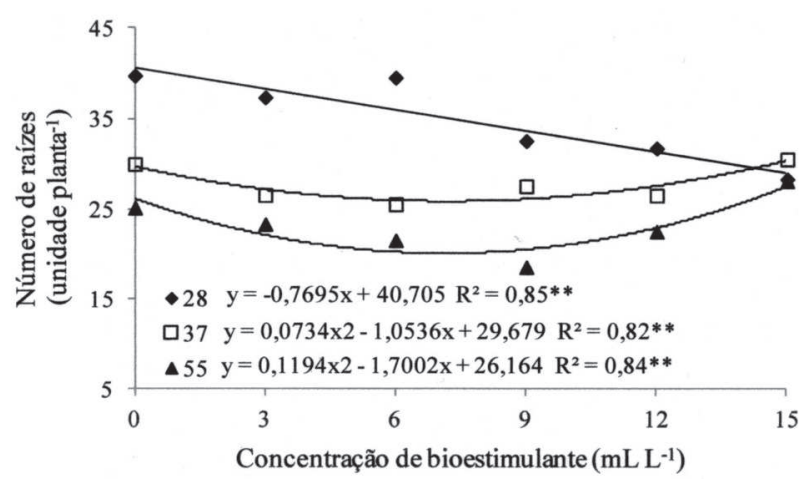

Figura 2: Número de raízes por planta, em função de concentração de bioestimulante e de épocas de coleta. **Significativo a $1 \%$ de probabilidade pelo teste $\mathrm{F}$. 
quadrático, com incrementos em função da maior permanência das plantas nos recipientes.

Dessa forma, embora tenha ocorrido variação no número de raízes em algumas épocas de coleta, a massa seca das raízes foi ampliada com o aumento do tempo de permanência das plantas nos recipientes, o que indica que, quando houve redução do número de raízes, a massa seca de cada raiz foi ampliada, de maneira a permitir maior exploração do substrato.

De maneira semelhante à deste trabalho, Cândido et al. (2012) verificaram que a imersão de estacas de canelinha em solução de $5 \mathrm{~mL} \mathrm{~L}^{-1}$ de Stimulate $^{\circledR}$ não proporcionou resultados diferentes dos da testemunha, nas diferentes variáveis avaliadas, entre elas a massa seca de raízes. Contudo, Cato (2006) observou que a aplicação de Stimulate ${ }^{\circledR}$ promoveu incrementos significativos sobre o acúmulo de matéria seca, nas raízes de tomateiro, em comparação com o do controle. Dessa forma, os resultados obtidos não confirmaram a atuação do produto como estimulador do sistema radicular e, consequentemente, o favorecimento da absorção de água e de nutrientes pela planta, até a concentração de $15 \mathrm{~mL} \mathrm{~L}^{-1}$.

Com relação à parte aérea da planta, houve interação entre as concentrações de bioestimulante e as épocas de coleta para o número de folhas, nas épocas 46 e 55 DAP (Figura 4). O número de folhas por planta não foi influenciado pela utilização de biofertilizante aos 10 , 19, 28 e 37 DAP, sendo seus valores médios 1,9; 12,9; 21,3 e 22,85 unidades, respectivamente. Nos demais períodos, 46 e 55 DAP, houve aumento do número de folhas com o incremento da concentração de bioestimulante, até os valores de 13,5 e 9,1 $\mathrm{mL} \mathrm{L}^{-1}$, respectivamente, quando foram atingidos os valores de 24,4 e 23,7 folhas por planta. Concentrações superiores a essas promoveram queda da produção de folhas.

Em estacas de figueira, Pio et al. (2006) não verificaram influência da aplicação de $2000 \mathrm{mg} \mathrm{L}^{-1}$ de ácido indolbutírico no número de folhas. Por outro lado, Villa et al. (2003) constataram que a utilização de AIB no enraizamento de estacas de amoreira-preta cv. Brazos

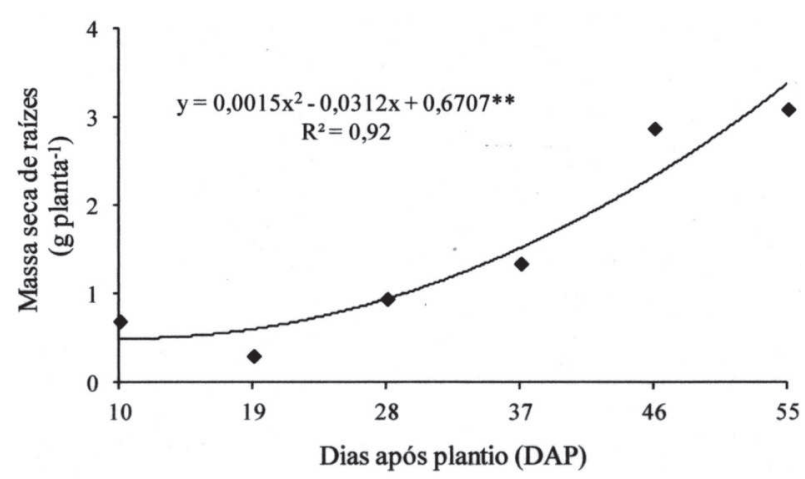

Figura 3: Massa seca de raízes por planta, em função da época de coleta. **Significativo a $1 \%$ de probabilidade pelo teste $\mathrm{F}$. promoveu redução em todas as variáveis (incluindo percentagem de enraizamento e número de folhas), o que foi atribuído à possibilidade de as estacas já apresentarem conteúdo endógeno de auxinas apropriado para o processo de enraizamento, e a aplicação de AIB possivelmente induziu um efeito fitotóxico nas estacas.

Não houve interação entre concentração de bioestimulante e época de coleta, para a variável massa seca de folhas. A característica não foi influenciada pela utilização de biofertilizante, sendo seu valor médio de 1,28 g por planta. A massa seca variou em função da época de coleta, respondendo segundo modelo quadrático, com valor máximo de 2,2 g por planta aos 51,3 DAP (Figura 5).

A relação entre número e massa seca de folhas indica que nas épocas em que o número de folhas não variou em função do bioestimulante, ou seja, 10, 19, 28 e 37 DAP, a massa de matéria seca foi aumentada em função da ampliação do período de permanência das plantas nos recipientes. Dessa forma, as folhas apresentaram maior massa seca individual, provavelmente por aumento de sua área ou por ampliação de sua espessura com o passar do tempo. Nas épocas 46 e 55 DAP, embora tenha ocorrido variação do número de folhas em função das doses do bioestimulante, no período compreendido entre essas

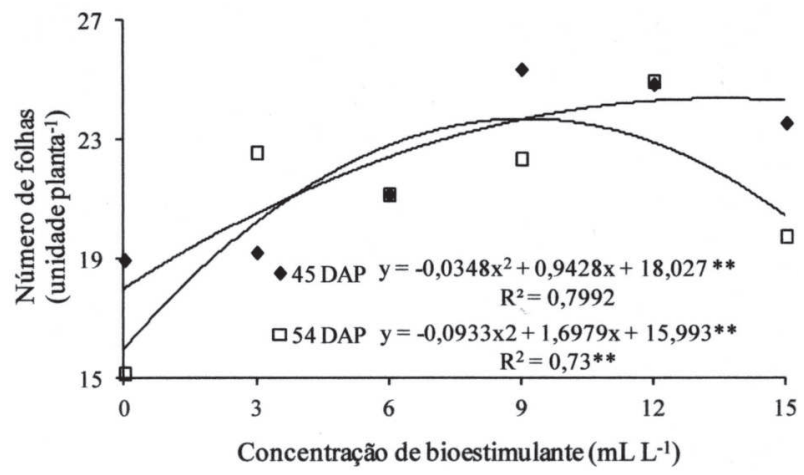

Figura 4: Número de folhas por planta, em função de concentração de bioestimulante e de épocas de coleta. **Significativo a $1 \%$ de probabilidade pelo teste $\mathrm{F}$.

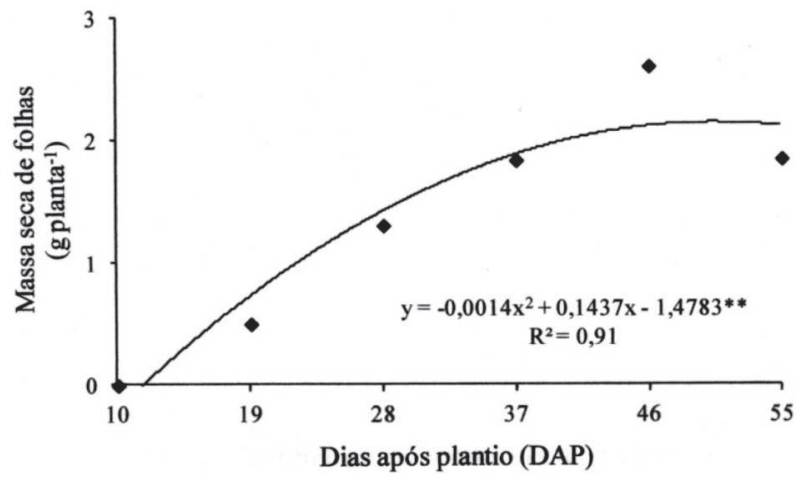

Figura 5: Massa seca de folhas por planta, em função da época de coleta. **Significativo a $1 \%$ de probabilidade pelo teste $\mathrm{F}$. 
duas datas ocorreram as maiores massas seca de folhas, em comparação com as das demais épocas de coleta.

A aplicação de bioestimulante em sorgo, no intervalo de concentrações de 10 a $13 \mathrm{~mL} \mathrm{~kg}^{-1}$ de sementes, e em trigo, no intervalo de concentrações de 3,5 a 5,0 mL $\mathrm{kg}^{-1}$ de sementes, proporcionou aumentos significativos na massa seca de parte aérea (Cato, 2006), comprovando que a utilização de bioestimulante também pode influenciar a porção aérea das plantas. No entanto, a influência do bioestimulante pode promover resultados desfavoráveis, como observado por Garcia et al. (2009), em cujo trabalho a utilização de Stimulate ${ }^{\circledR}$ na dose de 4 $\mathrm{mL} \mathrm{kg}^{-1}$ de semente, promoveu diminuição da massa seca de folhas, em solo fertilizado com fósforo, em comparação com a da testemunha, sem aplicação de Stimulate ${ }^{\circledR}$.

Com relação à produtividade de raízes tuberosas no campo, não houve diferença entre os tratamentos, conforme é possível verificar na Tabela 1 . As médias das produtividades total e comercial foram 25,5 e 22,2 $\mathrm{t} \mathrm{ha}^{-1}$, respectivamente. Esse resultado corrobora as informações verificadas no trabalho de Rós et al. (2015), no qual não houve diferença de produtividade de raízes tuberosas de batata-doce, variedade Uruguaiana, oriundas de estacas imersas nas mesmas doses do bioestimulante estudado neste trabalho. A influência das concentrações de bioestimulante no número de raízes e de folhas, reveladas no experimento conduzido em casa de vegetação, e que provavelmente também ocorreu no campo, não resultou em alteração de produtividade de raízes tuberosas.

Em batata, Blat et al., (2010), Guimarães et al. (2011) e Lima Junior et al. (2012) também verificaram produtividades de tubérculos semelhantes entre os tratamentos com e sem utilização de Stimulate ${ }^{\circledR}$, em diversas formas de aplicação. Contudo, Abrantes et al. (2011), Bertolin et al. (2010), Albrecht et al. (2009) e Palangana et al. (2012) verificaram incrementos de produtividade de feijoeiro, soja, algodoeiro e pimenteiro, respectivamente, quando há aplicação de doses adequadas de bioestimulantes. Ressalta-se, ainda, que, de acordo com

Tabela 1: Resumo das análises de variância para produtividades total (PT) e comercial (PC)

\begin{tabular}{lccc}
\hline \multirow{2}{*}{ Fonte de variação } & GL & \multicolumn{2}{c}{ Quadrado Médio } \\
\cline { 3 - 4 } & & PT & PC \\
\hline Tratamentos & 5 & $2,566^{\mathrm{ns}}$ & $2,342^{\mathrm{ns}}$ \\
Blocos & 4 & $30,461^{\mathrm{ns}}$ & $4,24^{\mathrm{ns}}$ \\
Erro & 20 & 10,151 & 7,93 \\
Total & 29 & & \\
\hline CV $(\%)$ & & 12,50 & 12,69 \\
Média geral & & 25,48 & 22,19 \\
\hline
\end{tabular}

ns - Não significativo pelo Teste F a 5\% de probabilidade de erro.
Mortele et al. (2008), a eficácia do biorregulador é favorecida quando há condição climática adversa.

Assim, novos estudos fazem-se necessários, a fim de identificar possíveis concentrações do produto que possam resultar em incremento de produtividade da cultura da batata-doce, bem como verificar, caso o produto favoreça o aumento de produtividade, a viabilidade econômica da utilização de bioestimulante na cultura.

\section{CONCLUSÃO}

A utilização do bioestimulante interfere no número de raízes adventícias e de folhas de plantas de batatadoce, mas não na produtividade de raízes tuberosas, até a concentração de $15 \mathrm{~mL} \mathrm{~L}^{-1}$.

\section{REFERÊNCIAS}

Abrantes FL, Sá ME, Souza LCD, Silva MP, Simidu HM, Andreotti M, Buzetti S, Valério Filho VV \& Arruda N (2011) Uso de regulador de crescimento em cultivares de feijão de inverno. Pesquisa Agropecuária Tropical, 41:148-154.

Albrecht LP, Braccini ADL, Ávila MR, Barbosa MC, Ricci TT\& Albrecht AJrP (2009) Aplicação de biorregulador na produtividade do algodoeiro e qualidade de fibra. Scientia Agraria, 10:191-198.

Bertolin DC, Sá ME, Arf O, Furlani Junior E, Colombo AS \& Carvalho FLBM (2010) Aumento da produtividade de soja com a aplicação de bioestimulantes. Bragantia, 69:339-347.

Blat SF, Suguino E, Branco RBF, Perdoná MJ, Scarpellini JR \& Gintilin Junior O (2010) Reguladores vegetais no crescimento e produção da batata. Disponível em: <http://www.aptaregional.sp.gov.br/acesseos-artigos-pesquisa-e-tecnologia/edicao-2010/2010-janeiro-junho/ 739-reguladores-vegetais-no-crescimento-e-producao-da-batata/ file.html> . Acessado em: 20 de abril de 2014.

Cândido WDS, Silva RCPD, Maia SSS, Silva ACD \& Coelho MDFB (2012) Propagação da canelinha (Croton zehntneri Pax et Hoffm.) por estacas caulinares. Revista Verde de Agroecologia e Desenvolvimento Sustentável, 7:45-49.

Castro PRC \& Vieira EL (2001) Aplicação de reguladores vegetais na agricultura tropical. Guaíba, Agropecuária. 132p.

Cato SC (2006) Ação de bioestimulante nas culturas do amendoizeiro, sorgo e trigo e interações hormonais entre auxinas citocininas e giberelinas. Tese de Doutorado. Escola Superior de Agricultura "Luiz de Queiroz", Piracicaba. 73p.

Garcia RA, Gazola E, Merlin A, Villas Bôas RL \& Crusciol CAC (2009) Crescimento aéreo e radicular de arroz de terras altas em função da adubação fosfatada e bioestimulante. Bioscience Journal, 25:65-72.

Guimarães RS, Lima JRS, Factor TL, Feltran JC, Calori AH \& Santtelo MC (2011) Avaliação da eficácia agronômica do Stimulate ${ }^{\circledR}$ e Nitrate Balance ${ }^{\circledR}$ na cultura da batata (Solanum tuberosum L.). In: $51^{\circ}$ Congresso Brasileiro de Olericultura, Viçosa. Anais, ABH. p.2724-2730.

Guimarães VF, Echer MM, Ribeiro KS, Pazuch D, Grabowski MMS, Davi JJS \& Layter NA (2006) Desenvolvimento e produtividade da alface americana em resposta a aplicação de bioestimulante nas mudas no momento do transplantio. In: $46^{\circ}$ Congresso Brasileiro de Olericultura, Goiânia. Anais, ABH. p.577-580.

Instituto Brasileiro de Geografia e Estatística - IBGE (2013) Sistema IBGE de recuperação automática - SIDRA. Banco de dados Agregados. Disponível em: http://www.sidra.ibge.gov.br/bda/tabela/ protabl.asp?c=99\&z=t\&o=11\&i=P. Acessado em: 10 de setembro de 2014 
Lima Junior S, Factor TL, Feltran JC, Silveira JM \& Calori AH (2012) Avaliação da eficácia agronômica de biostimulante e fertilizante folia na cultura da batata. In: $52^{\circ}$ Congresso Brasileiro de Olericultura, Salvador. Anais, ABH. p.S3337-S3344.

Miguel FB, Silva JAA, Bárbaro IM, Esperancini MST, Ticelli M \& Costa AGF (2009) Viabilidade econômica na utilização de um regulador vegetal em cana-planta. Informações Econômicas, 39:53-59.

Mortele LM, Santos RF, Braccini AL, Scapim CA \& Barbosa MC (2008) Efeito da aplicação de biorregulador no desempenho agronômico e produtividade da soja. Acta Scientiarum Agronomy, 30:701-709.

Palangana FC, Silva ES, Goto R \& Ono EO (2012) Ação conjunta de citocinina giberelina e auxina em pimentão enxertado e não enxertado sob cultivo protegido. Horticultura Brasileira, 30:751-755.

Pio R, Ramos JD, Chalfun NNJ, Gontijo TCA, Mendonça V, Carrijo EP \& Chagas EA (2006) Propagação de estacas apicais de figueira: diferentes ambientes, ácido indolbutírico e tipo de estaca. Ciência e Agrotecnologia, 30:1021-1026.
Reddy JRS, Krisnappa KS \& Nagarajaiah C (1991) Effect of fito-horm on the yield attributes and yield of potato. Mysore Journal of Agricultural Sciences, 25:350-354.

Reghin MY, Otto RF\& Silva JBC (2000) “Stimulate Mo” e proteção com "tecido-não-tecido" no pré enraizamento de mudas de mandioquinha salsa. Horticultura Brasileira, 18:53-56.

Rós AB, Montes SMNM, Narita N \& Tavares Filho J (2011) Technical viability of the production of sweet potatoes plantlets in trays. Semina: Ciências Agrárias, 32:1423-1428.

Rós AB, Narita N \& Araújo HSde (2015) Uso de regulador de crescimento na cultura da batata-doce. Científica, 43:135-142.

Taiz L \& Zeiger E (2006) Fisiologia vegetal. $3^{\mathrm{a}}$ ed. Porto Alegre, Artmed. 719p.

Villa F, Pio R, Chalfun NNJ, Gontijo TCA \& Dutra LF (2003) Propagação de amoreira-preta utilizando estacas lenhosas. Ciência e Agrotecnologia, 27:829-834. 